\title{
Effects of Hydrolysis and Carbonization Reactions on Hydrochar Production
}

\author{
K. Fakkaew ${ }^{\mathrm{a},}{ }^{*}$, T. Koottatep ${ }^{\mathrm{a}}$, C. Polprasert ${ }^{\mathrm{b}}$ \\ ${ }^{a}$ Environmental Engineering and Management, School of Environment Resources and \\ Development, Asian Institute of Technology, Thailand \\ ${ }^{\mathrm{b}}$ Department of Civil Engineering, Faculty of Engineering, Thammasat University,
} Thailand

\begin{abstract}
Hydrothermal carbonization (HTC) is a thermal conversion process which converts wet biomass into hydrochar. In this study, a low-energy HTC process named "Two-stage HTC" comprising of hydrolysis and carbonization stages using faecal sludge as feedstock was developed and optimized. The experimental results indicated the optimum conditions of the two-stage $\mathrm{HTC}$ to be; hydrolysis temperature of $170{ }^{\circ} \mathrm{C}$, hydrolysis reaction time of 155 min, carbonization temperature of $215^{\circ} \mathrm{C}$, and carbonization reaction time of $100 \mathrm{~min}$. The hydrolysis reaction time and carbonization temperature had a statistically significant effect on energy content of the produced hydrochar. Energy input of the two-stage HTC was about 25\% less than conventional HTC. Energy efficiency of the two-stage HTC for treating faecal sludge was higher than that of conventional HTC and other thermal
\end{abstract}

\footnotetext{
${ }^{*}$ Corresponding author, E-mail address: p-krai@ hotmail.com
} 
conversion processes such as pyrolysis and gasification. The two-stage HTC could be considered as a potential technology for treating FS and producing hydrochar.

Keywords:

Hydrothermal carbonization

Hydrochar

Faecal sludge

Hydrolysis

Carbonization

\section{Introduction}

Hydrothermal carbonization (HTC) is a thermal conversion process which was found to be effective in converting high moisture biomass into carbonaceous solids, commonly called hydrochar (Libra et al., 2011). According to previous reports (Falco et al., 2011; Funke and Ziegler, 2010; He et al., 2013; Sevilla and Fuertes, 2009), the hydrochar can be formed via two major conversion pathways: (1) direct solid-solid conversion of original biomass materials which undergoes devolatilization, intramolecular condensation, dehydration and decarboxylation, and (2) conversion of aqueous dispersion biomass materials which is dominated by reaction mechanisms including hydrolysis, dehydration, decarboxylation, fragmentation, polymerization and aromatization. 
The advantage of HTC for treating faecal sludge (FS) is that it requires minimal FS drying. However, the challenges of HTC process are the high energy consumption and relatively low energy content of the produced hydrochar. Therefore, a low-energy HTC process named "Two-stage HTC" was explored in this research.

The concept of the two-stage HTC process is to separate reaction pathways into two stages, namely hydrolysis and carbonization stages which are different in the conversion reactions and operating temperatures (Fig. 1). In the hydrolysis stage, biomass materials are broken down to become low-molecular weight compounds such as oligosaccharides, glucose (or fructose), and amino acids (Funke and Ziegler, 2010; He et al., 2013) which can be occurred in the temperature range of $100-175^{\circ} \mathrm{C}$ (Abelleira et al., 2012). The carbonization stage consists of the solid-solid conversion, dehydration and polymerization/aromatization reactions which require relatively high temperatures in the range of $160-280^{\circ} \mathrm{C}$ (Falco et al., 2011). In this stage, the hydrolyzed products (i.e. glucose or fructose) are dehydrated to 5-hydroxymethylfurfural (HMF) and subsequently polymerized and condensed to form the hydrochar (Sevilla and Fuertes, 2009). Simultaneously, the hydrochar is also formed via the solid-solid conversion of biomass materials (Falco et al., 2011). Based on this concept, the two-stage HTC should consume lower energy and result higher energy contents of the produced hydrochar than the conventional HTC.

In this study, the two-stage HTC using FS as feedstock was developed and optimized. The specific objectives of the research were to determine the effects of the process parameters such as temperature and reaction time of the hydrolysis and 
carbonization stages on the energy content of the produced hydrochar, to determine optimum conditions of the two-stage HTC that would result in low-energy input and high normalized energy yield and compared with the conventional HTC and other thermal conversion processes, and to analyze mass balance and carbon distribution of the two-stage HTC treating FS.

\section{Materials and Methods}

\subsection{FS samples and HTC reactor}

FS samples were collected from a municipal emptying truck which serviced residential areas in a city located near Bangkok, Thailand. Moisture contents of the collected FS samples, which were originally about $95 \%$ wt, were adjusted to be $80 \%$ wt using water bath before feeding to the HTC reactor. The 1-L high pressure reactor made of stainless steel and equipped with pressure gauge, thermocouple and gas collecting ports, as illustrated on Fig. 2, was used in this study. An electric heater equipped with a control panel (Fig. 2a) was used to adjust temperature and reaction time of the reactor.

\subsection{HTC experiments}

Two-stage HTC experiments were conducted by varying the hydrolysis temperature, hydrolysis reaction time, carbonization temperature, and carbonization 
reaction time, while energy content of the produced hydrochar was the responsive value. The design of the experiments showed in Table 1 was according to response surface methodology (RSM) with central composite design (Montgomery, 2005) using the Minitab-17 software. For comparison, the experiments of the conventional HTC of FS were also conducted with operating temperature of $250{ }^{\circ} \mathrm{C}$ and reaction time of $300 \mathrm{~min}$ obtained from an earlier research (Fakkaew, Unpublished results).

For each experiment, $350 \mathrm{~mL}$ of the FS sample was fed to the reactor which was operated at the designed temperature and reaction time of the hydrolysis stage, and subsequently at the designed temperature and reaction time of the carbonization stage (Table 1). At the end of each experiment, the reactor was rapidly cooled to the ambient temperature with water in a cooling jacket at the cooling rate of about $45^{\circ} \mathrm{C} / \mathrm{min}$ to quench the reaction. After collection of the gas samples, the carbonized FS remaining in the reactor was separated for solid (hydrochar) and liquid products using vacuum filtration (Whatman filter paper, $1.2 \mu \mathrm{m}$ ). The produced hydrochar was subsequently dried in an oven at $105{ }^{\circ} \mathrm{C}$ for at least $12 \mathrm{~h}$ to remove the remaining moisture. The produced hydrochar, liquid, and gas samples were analyzed for their characteristics as described in the following section.

\subsection{Analytical methods}

Energy content of the produced hydrochar was determined by a bomb calorimeter (AC500, Leco, USA), while energy consumption during the HTC operating was measured 
by a watt-hour meter (Mitsubishi, Thailand). The proximate analysis (moisture, volatile matter (VM), fixed carbon (FC), and ash contents) and ultimate analysis (carbon, hydrogen, nitrogen, and sulfur) of the produced hydrochar were measured using a thermogravimetric analyzer (TGA701, Leco, USA) and CHNS analyzer (Truspec, Leco, USA), respectively. Total organic carbon (TOC), chemical oxygen demand (COD) concentrations, total nitrogen (TN), and total phosphorus (TP) of liquid samples were analyzed using high temperature combustion method (TOC-V CPH, Shimadzu, Japan), closed dichromate reflux method, persulfate method, and colorimetric method (APHA, 2005), respectively. Gas samples were analyzed for; $\mathrm{CO}_{2}, \mathrm{CH}_{4}, \mathrm{O}_{2}$, and $\mathrm{N}_{2}$ using a gas chromatograph instrument (GC 7890A, Agilent, USA) equipped with FID detector.

\section{Results and Discussion}

\subsection{Effects of process parameters}

Based on these experimental results (Table 1), surface and contour plots of the energy contents of the produced hydrochar vs the process parameters were developed as shown in Fig. 3. The analysis of variance (ANOVA) showed $p$-values of process parameters such as the hydrolysis temperature, hydrolysis reaction time, carbonization temperature, and carbonization reaction time to be $0.62,0.01,0.05$, and 0.30 , respectively, which indicated the significances of the hydrolysis reaction time and carbonization temperature on the energy content of the produced hydrochar. The effects of process 
parameters on energy content of the produced hydrochar and the optimum conditions of the two-stage HTC are discussed in the following sections.

\subsubsection{Hydrolysis stage}

Process parameters of the hydrolysis stage in the two-stage HTC include temperature and reaction time. Fig. 3 (a) indicated that increasing the hydrolysis reaction time from 20 to $200 \mathrm{~min}$ resulted in the increased energy content of the produced hydrochar. The energy contents of the produced hydrochar were greater than $20 \mathrm{MJ} / \mathrm{kg}$ at hydrolysis temperatures and reaction times of $150-175^{\circ} \mathrm{C}$ and $150-200$ min, respectively. Results of the hydrolysis stage of HTC operation indicated that the VM contents were reduced from $60 \%$ in the initial FS to about $50 \%$ in the produced hydrochar at the hydrolysis reaction times of $\geq 150 \mathrm{~min}$, while the $\mathrm{FC}$ contents were relatively constant at all the hydrolysis reaction times.

At the hydrolysis temperature range of $150-180{ }^{\circ} \mathrm{C}$, lignocellulosic biomass as VM content in FS was hydrolyzed. Operating the hydrolysis stage at reaction times longer than 150 min might allow more production of oligomers and glucose which would be subsequently dehydrated and polymerized in the carbonization stage giving the products such as HMF, other soluble products and hydrochar (Sevilla and Fuertes, 2009). 


\subsubsection{Carbonization stage}

The effects of the carbonization temperature and reaction time on energy content of the produced hydrochar are shown in Fig. 3 (b). It can be seen that increasing the carbonization temperature from 200 to $250{ }^{\circ} \mathrm{C}$ resulted in the increased energy contents of the produced hydrochar. Fig.3 (b) indicates the energy contents of the produced hydrochar to be greater than $20 \mathrm{MJ} / \mathrm{kg}$ at the carbonization temperature range of $230-250{ }^{\circ} \mathrm{C}$. With respect to the carbonization reaction time, energy contents of the produced hydrochar tended to decrease with increasing the reaction time. If the energy contents of the produced hydrochar were expected to be greater than $20 \mathrm{MJ} / \mathrm{kg}$, the carbonization reaction times should be 100-250 min.

At the carbonization stage, the VM contents were further degraded from $50 \%$ to about $40 \%$ while the FC contents in the produced hydrochar were increased from $10 \%$ to about $15 \%$ which were attributed to the carbonization of the hydrolyzed VM. It could be hypothesized that reduction of the VM was due to the hydrolysis reaction and the hydrolyzed products were subsequently dehydrated and polymerized to become hydrochar, soluble products and gases. The increase of FC and decrease of VM contents during the two-stage HTC resulted in the increased energy content of $13.8 \mathrm{MJ} / \mathrm{kg}$ in the dry initial FS to about $20.0 \mathrm{MJ} / \mathrm{kg}$ in the produced hydrochar.

Previous researchers working on conventional (or single-stage) HTC found that increasing temperature resulted in increased dehydration and hydrochar formation reactions (Falco et al., 2011; Sevilla and Fuertes, 2009), hence energy contents of the 
produced hydrochar were found to correspondingly increase. Similar effects of the increased temperature on the conventional HTC of various feedstocks were also reported in the literatures (Danso-Boateng et al., 2013; Liu et al., 2013; Lu et al., 2013; Parshetti et al., 2013).

\subsection{Optimum conditions of two-stage HTC}

In this study, the optimum conditions of the two-stage HTC were based on the normalized energy yield which is defined as the energy of the produced hydrochar per mass of the dry initial feedstock (Li et al., 2013), as show in Table 2 (Eq. (1)). It could be deduced from the results in Fig. 4 that optimum conditions to produce the highest normalized energy yields of $13.9 \mathrm{MJ} / \mathrm{kg}$-FS were: hydrolysis temperature of $170{ }^{\circ} \mathrm{C}$, hydrolysis reaction time of $155 \mathrm{~min}$, carbonization temperature of $215^{\circ} \mathrm{C}$, and carbonization reaction time of $100 \mathrm{~min}$. To verify these optimum conditions, 3 replicates of the two-stage HTC experiments using different FS samples were conducted. These experimental results showed energy contents of the produced hydrochar and hydrochar yield to be $19.7,19.9$ and $20.8 \mathrm{MJ} / \mathrm{kg}$ and $72.8,70.7$ and $71.2 \%$, respectively, while the normalized energy yields of about $14.4 \mathrm{MJ} / \mathrm{kg}$ were achieved. Further evaluations of these optimum conditions with pilot- or full-scale two-stage HTC reactors treating FS or other biomass materials are recommended. 


\subsection{Mass balance and carbon distribution}

Mass balance and carbon distribution of the two-stage HTC, shown in Fig. 5, were carried out at the optimum conditions indicated in section 3.2. The carbon content of the initial FS was $38.1 \%$ wt and the other elements (e.g. hydrogen, nitrogen, oxygen, and sulfur) were $61.9 \%$ wt. The hydrothermally carbonized products, being hydrochar, liquid and gas, were found to be $72.8,23.7$ and $3.5 \% \mathrm{wt}$, respectively. The carbon distribution data indicated that $74.6 \%$ of carbon in the initial FS (38.1\%wt) retained within the hydrochar $(28.4 \% \mathrm{wt})$. The rest of carbon was shifted into either the liquid or gaseous products.

The liquid products still contained high concentrations of organic matters and nutrients as indicated by COD, TOC, TN, and TP concentrations (Table 3). The TOC concentration was used to calculate the carbon content in the liquid product which was 7.8\%wt of the initial FS. Analysis of HTC gas samples showed $\mathrm{CO}_{2}$ to be the main component $(64.1 \% \mathrm{v})$, similar to results of the conventional HTC of FS $(61.9 \% \mathrm{v})$ and other literatures (Berge et al., 2011; and Funke et al., 2013). From the mass balance analysis, about $5.0 \%$ of carbon in the initial FS was transferred into gas products (1.9\%wt). It is apparent that these liquid and gas products need to be further treated to minimize environmental pollutions, odor and greenhouse gas emissions. The liquid products could be treated by anaerobic digestion (Oliveira et al., 2013; Poerschmann et al., 2014) to produce the useful biogas, or applied to farmlands as liquid fertilizer (Polprasert, 2007). 


\subsection{Comparison to conventional HTC and thermal conversion processes}

This comparison of the available information and the experimental results focuses on the operating conditions and product distribution (Table 4), as well as energy efficiency (Table 5) for the thermal conversion processes such as pyrolysis, gasification, HTC and two-stage HTC, with the intent to examine the potential technology options for treating FS and producing valuable products. In general, the two-stage and conventional HTC processes could be operated at relatively lower temperatures and higher moisture contents of the feedstock than the two thermal conversion processes, but operating times of the HTC processes were relatively longer. The main advantage of the HTC processes is to produce hydrochar in the range of $50-80 \%$ wt while the pyrolysis yielded only $12-35 \%$ wt. Energy contents of the char product from these thermal conversion processes were in the same range of $11-36 \mathrm{MJ} / \mathrm{kg}$.

Energy efficiency can be defined as the ratio of the energy content of the product to the energy input (Xu and Lancaster, 2008). Based on $1 \mathrm{~kg}$ of dewatered FS feedstock at $80 \%$ moisture content, the energy efficiency of these thermal conversion processes could be determined using Eq. (2) in Table 2 and the results were compared in Table 5. Total energy inputs of pyrolysis and gasification (Table 5) were higher than the HTC processes because operations of pyrolysis and gasification processes require the dried feedstock which utilizes high energy for drying wet FS (80\% moisture content) during the pre-drying process. With respect to the HTC processes, the energy input of the two-stage HTC was about $25 \%$ less than the conventional HTC. The highest energy efficiency of 1.59 could be 
observed at the two-stage HTC which was higher than those for conventional HTC, pyrolysis and gasification processes.

The experimental results obtained from this study proved the advantages of the two-stage HTC over the conventional HTC, pyrolysis and gasification, such as the relatively high hydrochar yield and low energy required for heating the feedstock in the reactor to reach the desired temperatures and reaction times. To reduce the energy input for the HTC process, solar energy could be used in a drying bed technology for reducing the moisture content in feedstock prior feeding into HTC reactor and drying wet hydrochar produced after filtration process. The produced hydrochar can be used as solid fuels, soil amendment, energy storage, water purification and other value-added products (Libra et al., 2011; Titirici and Antonietti, 2010). Energy contents of the produced hydrochar could be further increased with the addition of some catalysts (Lynam et al., 2011 and 2012) and biomass (Heilmann et al., 2010; Oliveira et al., 2013).

With respect to scale-up, an increase in volume or capacity of production is usually an increasing investment cost but decreasing operation cost. In case of the HTC reactor, increase in size or volume of the reactor may affect heat transfer efficiency which might require longer operation time to complete the reactions. To avoid these scale-up effects on the HTC reactor, the following recommendations could be considered: (1) applying numbering-up (increasing number of rectors, not size of reactor) (Titirici, 2013) is a way to increase hydrochar production and avoid the effects of large-scale reactor; (2) determining optimal heating rate for the HTC operation, because too fast heating could lead to high difference of temperatures inside the reactor; (3) mixing of the reactor content to make the 
uniform heat distribution; and (4) heating the reactor from inside could be applied in the large-scale reactor for improving the heat transfer and reducing heat loss. However, it would be desirable to further evaluate cost-benefit analysis of full-scale two-stage HTC reactors treating FS or other biomass materials.

\section{Conclusions}

Based on the results obtained from this study, the optimum conditions for the twostage HTC of FS were: hydrolysis temperature of $170{ }^{\circ} \mathrm{C}$, hydrolysis reaction time of 155 min, carbonization temperature of $215^{\circ} \mathrm{C}$, and carbonization reaction time of $100 \mathrm{~min}$. Energy input of the two-stage HTC was about $25 \%$ less than the conventional HTC. Energy efficiency of the two-stage HTC using FS as feedstock was higher than those of conventional HTC, pyrolysis and gasification processes. Therefore, the two-stage HTC could be considered as a potential technology for treating FS and producing hydrochar.

\section{Acknowledgement}

This paper was based on the results of the project "Stimulating local innovation on sanitation for the urban poor in sub-Saharan Africa and Southeast Asia" funded by the Bill \& Melinda Gates Foundation. 


\section{References}

1. Abelleira, J., Perez-Elvira, S.I., Sanchez-Oneto, J., Portela, J.R., Nebot, E., 2012.

Advanced Thermal Hydrolysis of secondary sewage sludge: A novel process

combining thermal hydrolysis and hydrogen peroxide addition. Resour. Conserv.

Recycl. 59, 52- 57.

2. American Public Health Association (APHA), 2005. Standard methods for the examination of water and wastewater, $21^{\text {th }}$ edition. Washington DC.

3. Berge, N.D., Ro, K.S., Mao, J., Flora, J.R.V., Chappell, M.A., Bae, S., 2011.Hydrothermal Carbonization of Municipal Waste Streams. Environ. Sci. Technol. $45,5696-5703$.

4. Danso-Boateng, E., Holdich, R.G., Shama, G., Wheatley, A.D., Sohail, M., Martin S.J., 2013. Kinetics of faecal biomass hydrothermal carbonisation for hydrochar production. Appl. Energy. 111, 351-357.

5. Fakkaew, K., Unpublished results. Hydrochar production through two-stage hydrothermal carbonization of faecal sludge. Internal report, November 2014.

6. Falco, C., Baccile, N., Titirici, M.M., 2011. Morphological and structural differences between glucose, cellulose and lignocellulosic biomass derived hydrothermal carbons. Green Chem. 13, 3273-3281.

7. Funke, A., Reebs, F., Kruse, A., 2013. Experimental comparison of hydrothermal and vapothermal carbonization. Fuel Process. Technol. 115, 261-269. 
8. Funke, A., Ziegler, F., 2010. Hydrothermal carbonization of biomass: a summary and discussion of chemical mechanisms for process engineering. Biofuel Bioprod. Bioref. 4, 160-177.

9. Hamilton, C. J., 2000. Gasification as an innovative method of sewage-sludge disposal. J. Chart. Inst. Water Environ. Manag. 14, 89-93.

10. He, C., Giannis, A., Wanga, J.Y., 2013. Conversion of sewage sludge to clean solid fuel using hydrothermal carbonization: Hydrochar fuel characteristics and combustion behavior. Appl. Energy. 111, 257-266.

11. Heilmann, S.M., Davis, H.T., Jader, L.R., Lefebvre, P.A., Sadowsky, M.J., Schendel, F.J., Keitz, M.G., Valentas, K.J., 2010. Hydrothermal carbonization of microalgae. Biomass Bioenergy. 34, 875-882.

12. Kim, Y., Parker, W., 2008. A technical and economic evaluation of the pyrolysis of sewage sludge for the production of bio-oil. Bioresour. Technol. 99, 1409-1416.

13. Li, L., Diederick, R., Flora, J.R.V., Berge, N.D., 2013. Hydrothermal carbonization of food waste and associated packaging materials for energy source generation. Waste Manag. 33, 2478-2492.

14. Libra, J.A., Ro, K.S., Kammann, C., Funke, A., Berge, N.D., Neubauer, Y., Titirici, M.M., Fuhner, C., Bens, O., Kern, J., Emmerich, K.H., 2011. Hydrothermal carbonization of biomass residuals: a comparative review of the chemistry, processes and applications of wet and dry pyrolysis. Biofuel. 2(1), 89-124.

15. Liu, Z., Quek, A., a, Hoekman, S.K., Balasubramanian, R., 2013. Production of solid biochar fuel from waste biomass by hydrothermal carbonization. Fuel. 103, 943-949. 
16. Lu, X., Jordan, B., Berge, N.D., 2012. Thermal conversion of municipal solid waste via hydrothermal carbonization: Comparison of carbonization products to products from current waste management techniques. Waste Manag. 32, 1353-1365.

17. Lu, X., Pellechia, P.J., Flora, J.R.V., Berge, N.D., 2013. Influence of reaction time and temperature on product formation and characteristics associated with the hydrothermal carbonization of cellulose. Bioresour. Technol. 138, 180-190.

18. Lynam, J.G., Coronella, C.J., Yan, W., Reza, M.T., Vasquez, V.R., 2011. Acetic acid and lithium chloride effects on hydrothermal carbonization of lignocellulosic biomass. Bioresour. Technol. 102, 6192-6199.

19. Lynam, J.G., Reza, M.T., Vasquez, V.R., Coronella, C.J., 2012. Effect of salt addition on hydrothermal carbonization of lignocellulosic biomass. Fuel. 99, 271-273.

20. Montgomery D.C., 2005. Design and Analysis of Experiments, $6^{\text {th }}$ Edition. John Wiley \& Son, Inc, USA.

21. Oliveira, I., Blöhse, D., Ramke, H.G., 2013. Hydrothermal carbonization of agricultural residues. Bioresour. Technol. 142, 138-146.

22. Parshetti, G.K., Hoekman, S.K., Balasubramanian, R., 2013. Chemical, structural and combustion characteristics of carbonaceous products obtained by hydrothermal carbonization of palm empty fruit bunches. Bioresour. Technol. 135, 683-689.

23. Poerschmann, J., Weiner, B., Wedwitschka, H., Baskyr, I., Koehler, R., Kopinke, F.D., 2014. Characterization of biocoals and dissolved organic matter phases obtained upon hydrothermal carbonization of brewer's spent grain. Bioresour. Technol. 164, 162-169. 
24. Polprasert, C., 2007. Organic waste recycling: Technology and management, $3^{\text {rd }}$ edition. IWA publishing, UK.

25. Sevilla, M., Fuertes, A.B., 2009. The production of carbon materials by hydrothermal carbonization of cellulose. Carbon. 47, 2281-2289.

26. Titirici, M.M., Antonietti, M., 2010. Chemistry and materials options of sustainable carbon materials made by hydrothermal carbonization. Chem. Soc. Rev. 39, 103-116.

27. Xu, C., Lancaster, J., 2008. Conversion of secondary pulp/paper sludge powder to liquid oil products for energy recovery by direct liquefaction in hot-compressed water. Water Res. 42, 1571-1582. 


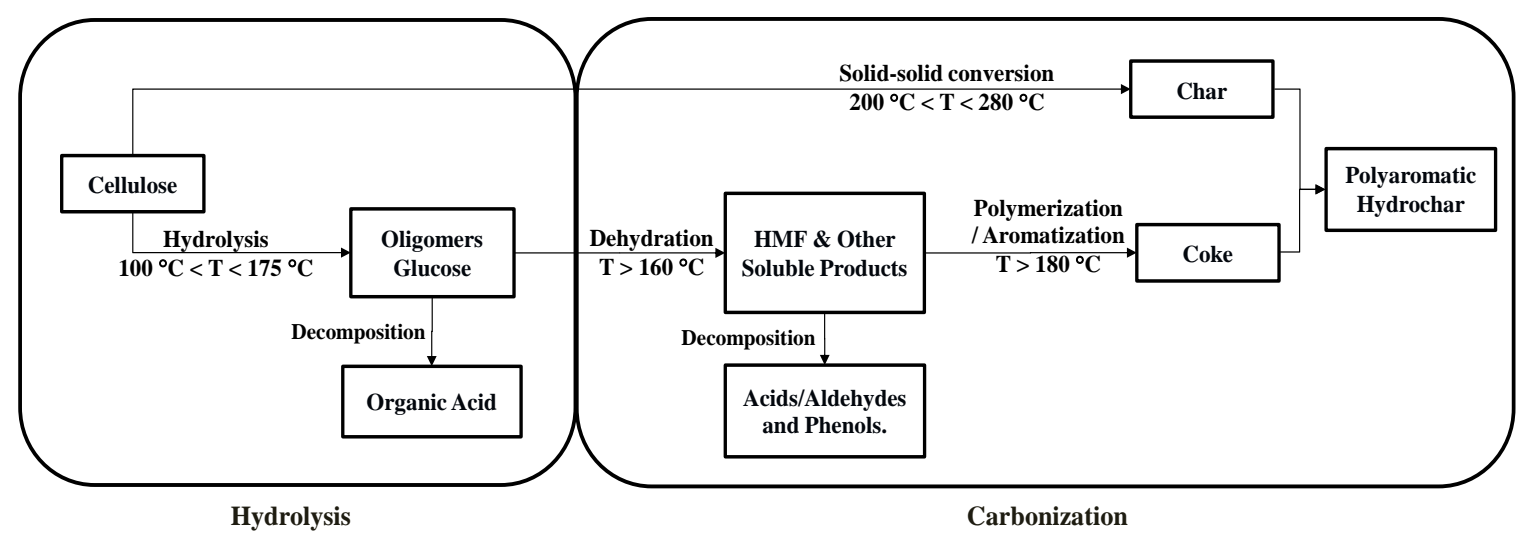

Fig. 1 Two-stage HTC reaction pathways 


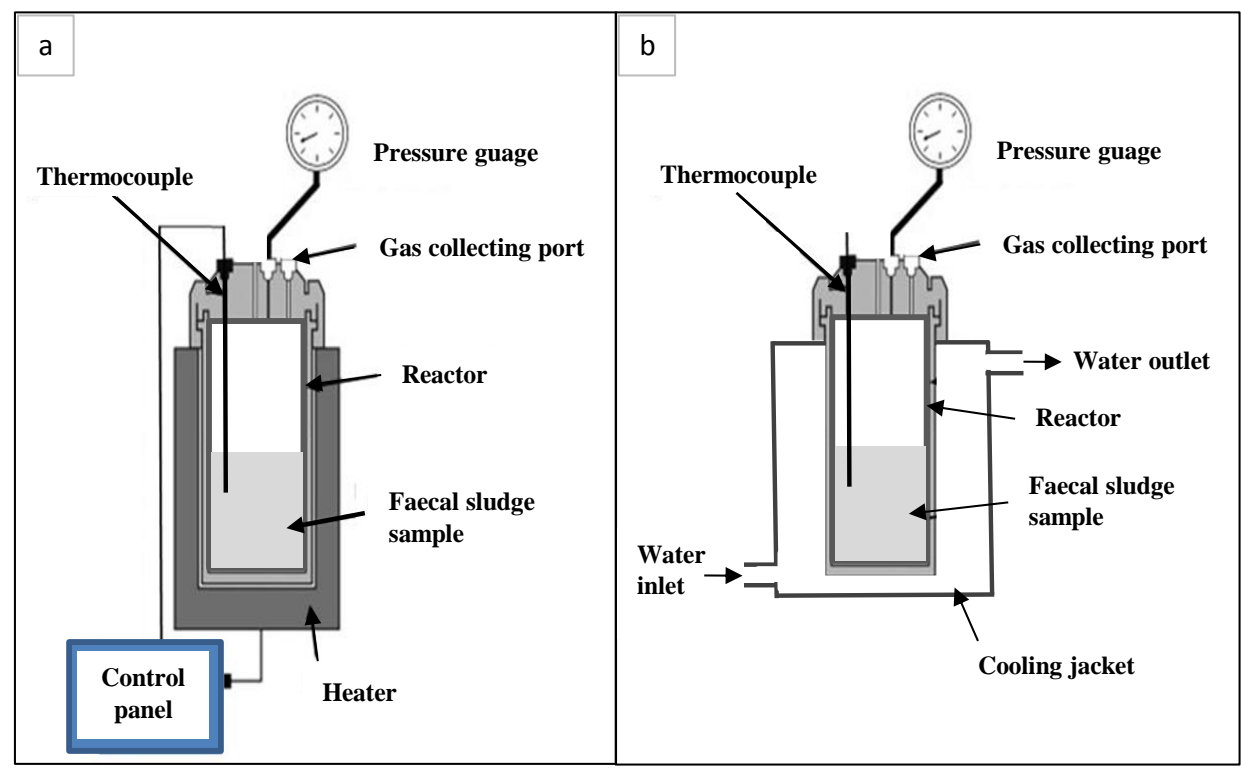

Fig. 2 Schematic of HTC reactor (a) heating system and (b) cooling jacket 


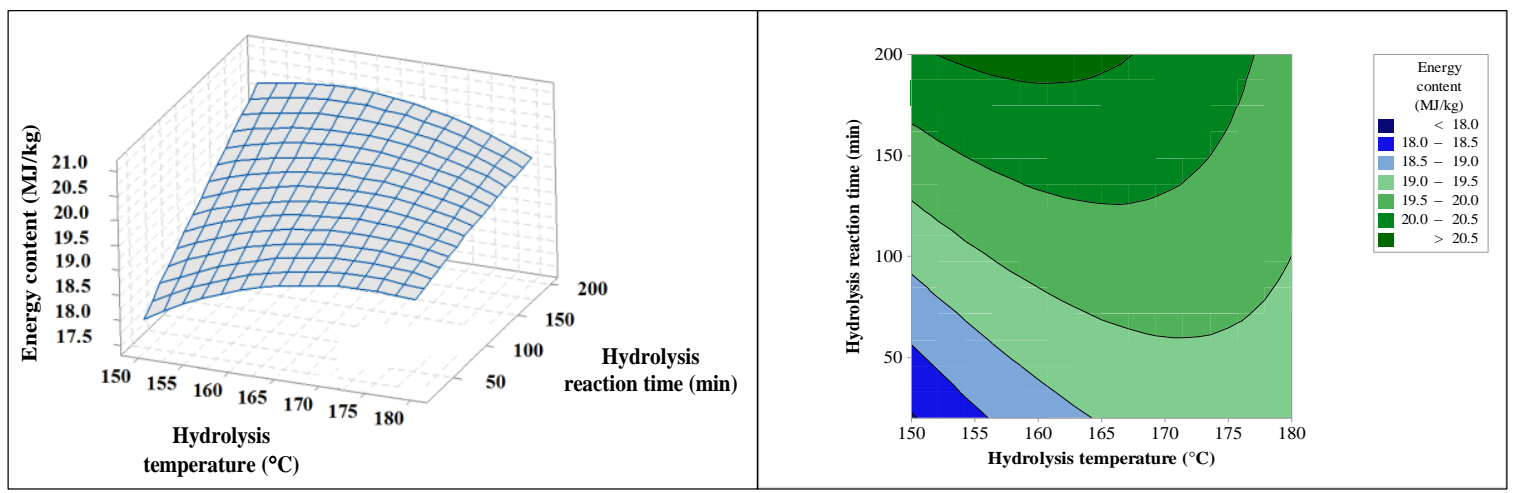

(a)

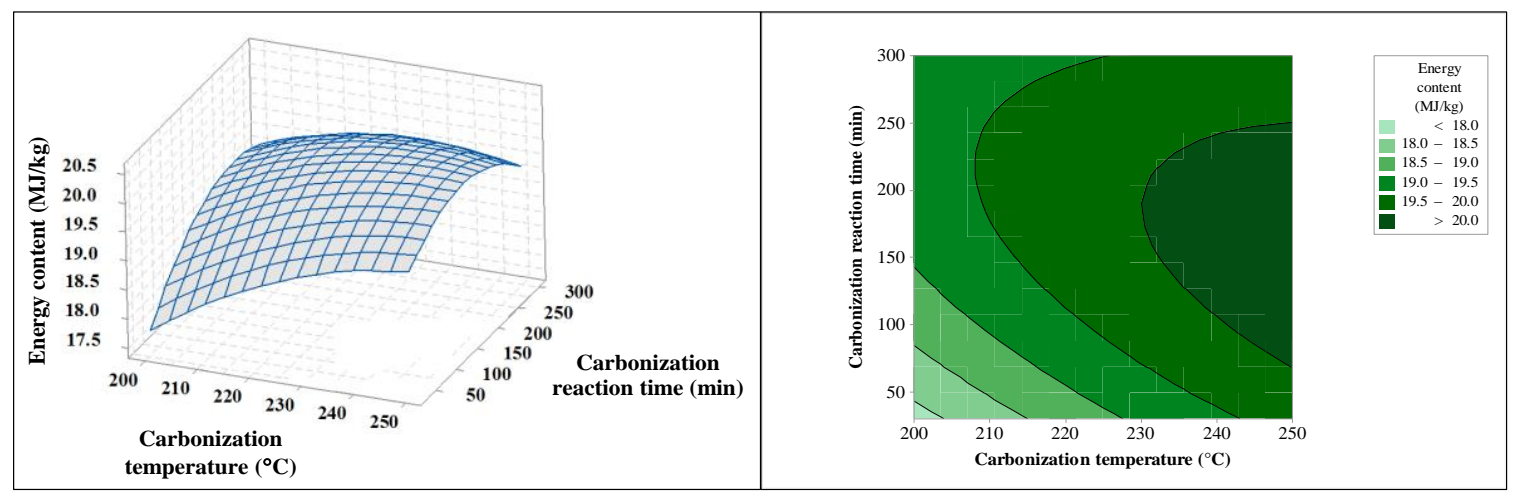

(b)

Fig. 3 Surface and contour plots of energy content vs process parameters: (a) hydrolysis temperature and hydrolysis reaction time, and (b) carbonization temperature and carbonization reaction time 


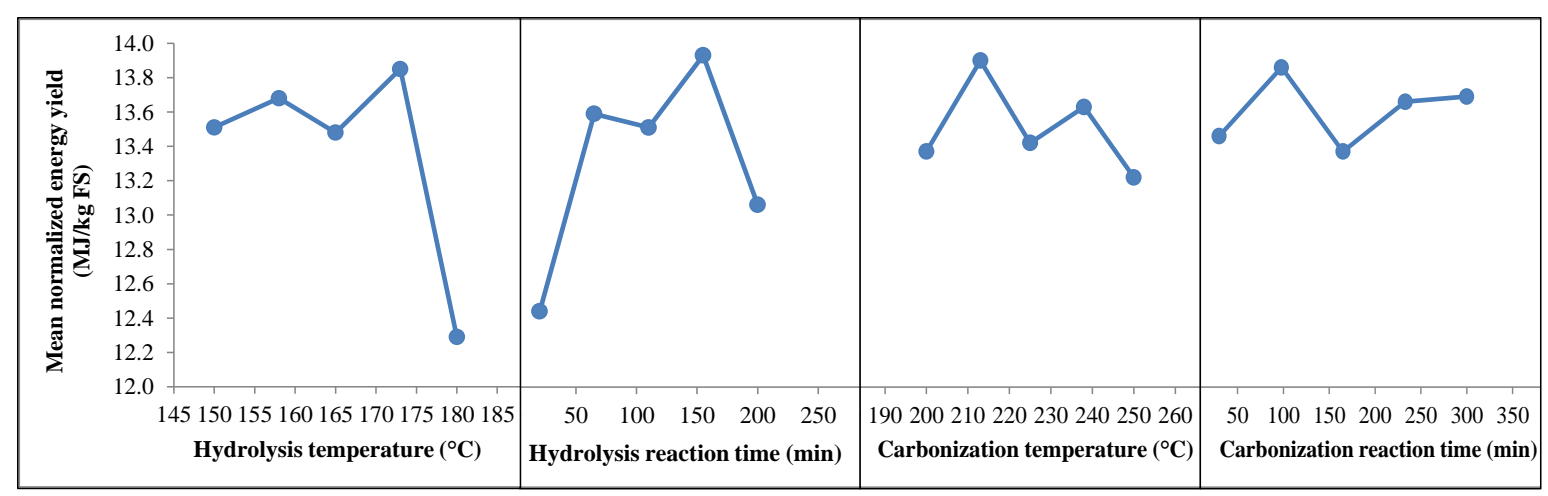

Fig. 4 Mean normalized energy yields at each process parameters of two-stage HTC of FS 


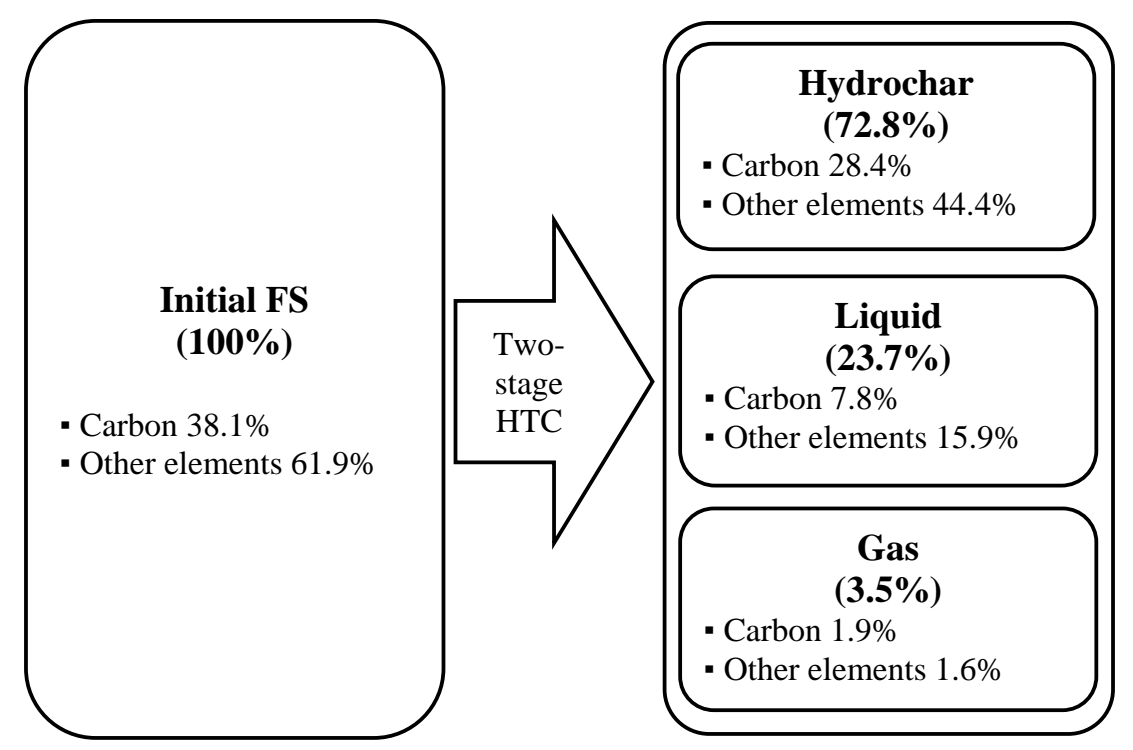

Fig. 5 Mass balance and carbon distribution for two-stage HTC of FS 
Table 1 Experimental design and results for two-stage HTC of FS

\begin{tabular}{|c|c|c|c|c|c|}
\hline \multirow[t]{2}{*}{ Run order } & \multicolumn{2}{|c|}{ Hydrolysis } & \multicolumn{2}{|c|}{ Carbonization } & \multirow{2}{*}{$\begin{array}{l}\text { Energy content } \\
(\mathrm{MJ} / \mathrm{kg})\end{array}$} \\
\hline & $\begin{array}{c}\text { Temperature } \\
\left({ }^{\circ} \mathrm{C}\right)\end{array}$ & $\begin{array}{l}\text { Reaction time } \\
\text { (min) }\end{array}$ & $\begin{array}{c}\text { Temperature } \\
\left({ }^{\circ} \mathrm{C}\right)\end{array}$ & $\begin{array}{l}\text { Reaction time } \\
\text { (min) }\end{array}$ & \\
\hline 1 & 150 & 110 & 225 & 165 & 19.82 \\
\hline 2 & 158 & 65 & 213 & 98 & 18.24 \\
\hline 3 & 158 & 65 & 213 & 233 & 18.58 \\
\hline 4 & 158 & 65 & 238 & 98 & 18.39 \\
\hline 5 & 158 & 65 & 238 & 233 & 19.46 \\
\hline 6 & 158 & 155 & 213 & 98 & 19.86 \\
\hline 7 & 158 & 155 & 213 & 233 & 18.69 \\
\hline 8 & 158 & 155 & 238 & 98 & 21.13 \\
\hline 9 & 158 & 155 & 238 & 233 & 20.14 \\
\hline 10 & 165 & 20 & 225 & 165 & 19.05 \\
\hline 11 & 165 & 110 & 200 & 165 & 19.05 \\
\hline 12 & 165 & 110 & 225 & 30 & 18.47 \\
\hline 13 & 165 & 110 & 225 & 165 & 20.34 \\
\hline 14 & 165 & 110 & 225 & 165 & 18.84 \\
\hline 15 & 165 & 110 & 225 & 165 & 19.53 \\
\hline 16 & 165 & 110 & 225 & 165 & 20.21 \\
\hline 17 & 165 & 110 & 225 & 165 & 20.77 \\
\hline 18 & 165 & 110 & 225 & 165 & 19.59 \\
\hline 19 & 165 & 110 & 225 & 300 & 19.96 \\
\hline 20 & 165 & 110 & 250 & 165 & 19.91 \\
\hline 21 & 165 & 200 & 225 & 165 & 20.00 \\
\hline 22 & 173 & 65 & 213 & 98 & 18.52 \\
\hline 23 & 173 & 65 & 213 & 233 & 20.29 \\
\hline 24 & 173 & 65 & 238 & 98 & 19.44 \\
\hline 25 & 173 & 65 & 238 & 233 & 19.05 \\
\hline 26 & 173 & 155 & 213 & 98 & 19.94 \\
\hline 27 & 173 & 155 & 213 & 233 & 19.95 \\
\hline 28 & 173 & 155 & 238 & 98 & 20.30 \\
\hline 29 & 173 & 155 & 238 & 233 & 20.24 \\
\hline 30 & 180 & 110 & 225 & 165 & 18.83 \\
\hline
\end{tabular}


Table 2 Summary equations

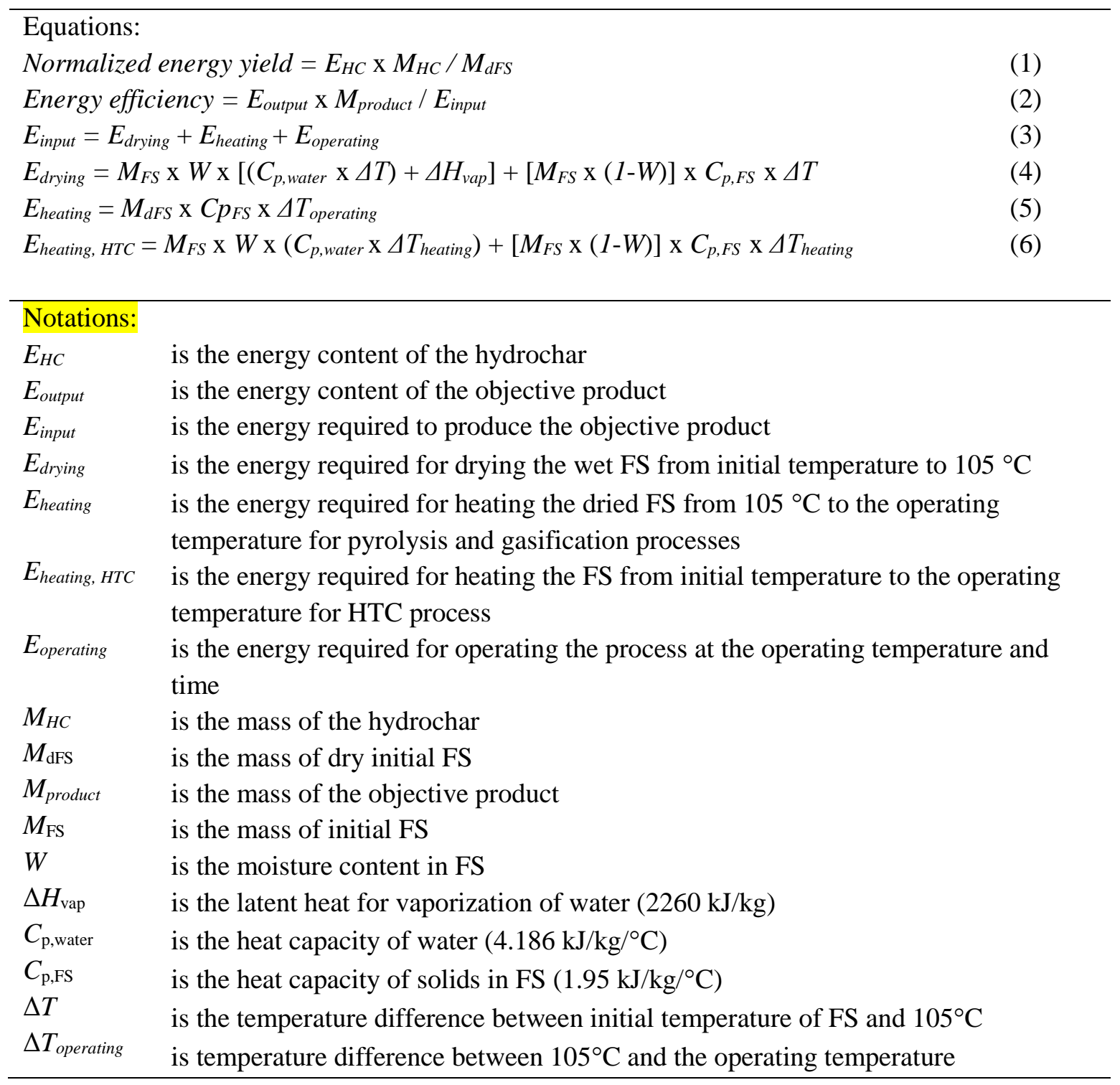

Adapted from Li et al. (2013), Xu and Lancaster (2008) and Kim and Parker (2008) 
Table 3 Characteristics of FS and liquid products

\begin{tabular}{lllcc}
\hline \multirow{2}{*}{ Parameters } & \multirow{2}{*}{ Unit } & FS $^{\mathrm{a}}$ & \multicolumn{2}{c}{ Liquid products } \\
\cline { 4 - 5 } TOC & $\mathrm{g} / \mathrm{L}$ & $16-40$ & $12-16$ & $29-30$ \\
$\mathrm{COD}$ & $\mathrm{g} / \mathrm{L}$ & $43-50$ & $25-31$ & $26-32$ \\
$\mathrm{TN}$ & $\mathrm{g} / \mathrm{L}$ & $5.5-7.5$ & $7.0-8.5$ & $5.0-6.2$ \\
TP & $\mathrm{mg} / \mathrm{L}$ & 100 & 0.78 & 1.50 \\
\hline
\end{tabular}

${ }^{\mathrm{a}}$ FS with moisture content of $80 \%$ wt 
Table 4 Comparison of operating condition, energy content and product distribution for thermal conversion processes

\begin{tabular}{|c|c|c|c|c|c|c|c|c|c|}
\hline \multirow[t]{4}{*}{ Process } & \multicolumn{2}{|c|}{ Operation } & \multirow{4}{*}{$\begin{array}{l}\text { Feed } \\
\text { stock }\end{array}$} & \multicolumn{6}{|c|}{ Product distribution } \\
\hline & \multirow[b]{3}{*}{ Temp $\left({ }^{\circ} \mathrm{C}\right)$} & \multirow[b]{3}{*}{ Time } & & \multicolumn{2}{|c|}{ Char } & \multicolumn{2}{|c|}{ Liquid } & \multicolumn{2}{|c|}{ Gas } \\
\hline & & & & \multirow{2}{*}{$\begin{array}{l}\text { Dist. } \\
\text { (\%wt.) }\end{array}$} & \multirow{2}{*}{$\begin{array}{l}\text { Energy } \\
(\mathrm{MJ} / \mathrm{kg})\end{array}$} & \multirow{2}{*}{$\begin{array}{l}\text { Dist. } \\
\text { (\%wt.) }\end{array}$} & \multirow{2}{*}{$\begin{array}{l}\text { Energy } \\
(\mathrm{MJ} / \mathrm{kg})\end{array}$} & \multirow{2}{*}{$\begin{array}{l}\text { Dist. } \\
\text { (\%wt.) }\end{array}$} & \multirow{2}{*}{$\begin{array}{l}\text { Energy } \\
\left(\mathrm{MJ} / \mathrm{m}^{3}\right)\end{array}$} \\
\hline & & & & & & & & & \\
\hline Pyrolysis ${ }^{\mathrm{a}, \mathrm{b}, \mathrm{c}}$ & $300-500$ & Sec-week & Dry & $12-35$ & $11-35$ & $30-75$ & $10-35$ & $13-35$ & $5-30$ \\
\hline Gasification ${ }^{b, c}$ & $800-1400$ & $10-20 \mathrm{sec}$ & Dry & 10 & NA & 5 & NA & 85 & $2-20$ \\
\hline $\mathrm{HTC}^{\mathrm{b}, \mathrm{c}}$ & $180-250$ & $1-72 \mathrm{~h}$ & Wet & $50-80$ & $18-36$ & $5-20$ & NA & $2-5$ & NA \\
\hline HTC of FS ${ }^{d}$ & 250 & $300 \mathrm{~min}$ & Wet & $70-74$ & $18-20$ & $19-21$ & $\begin{array}{c}\text { Not } \\
\text { analyzed }\end{array}$ & $7-9$ & $\begin{array}{c}\text { Not } \\
\text { analyzed }\end{array}$ \\
\hline $\begin{array}{l}\text { Two-stage } \\
\text { HTC of FS }\end{array}$ & $\begin{array}{l}170 \text { and } \\
215\end{array}$ & $\begin{array}{l}155 \text { and } \\
100 \text { min }\end{array}$ & Wet & $70-73$ & $20-21$ & $21-23$ & $\begin{array}{c}\text { Not } \\
\text { analyzed }\end{array}$ & $3-7$ & $\begin{array}{c}\text { Not } \\
\text { analyzed }\end{array}$ \\
\hline \multicolumn{10}{|c|}{$\mathrm{NA}=$ not available } \\
\hline \multicolumn{10}{|c|}{${ }^{\mathrm{a}}$ Depends on process (slow, intermediate and fast) } \\
\hline \multicolumn{10}{|c|}{${ }^{\mathrm{b}}$ Libra et al. (2011) } \\
\hline \multicolumn{10}{|c|}{${ }^{\mathrm{c}} \mathrm{Lu}$ et al. (2012) } \\
\hline${ }^{\mathrm{d}}$ Data fron & this study & & & & & & & & \\
\hline
\end{tabular}


Table 5 Comparison of energy efficiency for thermal conversion processes

\begin{tabular}{|c|c|c|c|c|c|c|}
\hline \multirow[b]{2}{*}{ Process } & \multicolumn{4}{|c|}{ Energy input (MJ) } & \multirow{2}{*}{$\begin{array}{c}\text { Energy } \\
\text { output } \\
(\mathrm{MJ})\end{array}$} & \multirow{2}{*}{$\begin{array}{l}\text { Energy } \\
\text { efficiency }\end{array}$} \\
\hline & $\begin{array}{c}\text { Pre- } \\
\text { drying }\end{array}$ & Operating & $\begin{array}{l}\text { Post- } \\
\text { drying }\end{array}$ & Total & & \\
\hline Pyrolysis $^{\text {a }}$ & 2.13 & 1.07 & - & 3.20 & 3.38 & 1.06 \\
\hline Gasification $^{\mathrm{b}}$ & 2.13 & 1.45 & - & 3.58 & 3.18 & 0.89 \\
\hline Conventional $\mathrm{HTC}^{\mathrm{c}}$ & - & 1.92 & 0.46 & 2.50 & 2.74 & 1.10 \\
\hline Two-stage HTC ${ }^{c}$ & - & 1.41 & 0.46 & 1.87 & 2.97 & 1.59 \\
\hline
\end{tabular}

Notes: (1) Based on $1 \mathrm{~kg}$ of dewatered FS feedstock (80\% moisture content) and (2) Original FS (about 95\% moisture content) could be pre-dewatered before feeding into the reactors by sedimentation, thickening, or drying bed, which were not included in this comparison

${ }^{\text {a }}$ Data from Kim and Parker (2008); pyrolysis of digested sludge at $500{ }^{\circ} \mathrm{C}$

${ }^{\mathrm{b}}$ Data from Hamilton (2000); gasification of dried sewage sludge with a circulating fluidized bed at $850{ }^{\circ} \mathrm{C}$

${ }^{\mathrm{c}}$ Data from this study 